\title{
Imperfect Forecasts and Decision Making in
}

\author{
Agriculture
}

\author{
Yoko Kusunose $^{\mathrm{a}}$ \\ University of Kentucky
}

Rezaul Mahmood ${ }^{\mathrm{b}}$

Western Kentucky University

April 11, 2016

\begin{abstract}
The past few decades saw tremendous advances in weather and climate forecasting ability. These advances opened up the possibility of strategic adaptation of agricultural management in anticipation of weather and climate outcomes, resulting in a profusion of studies estimating the value of weather and climate forecasts. Estimated values from this literature were, in many cases, substantive, implying that farmers could significantly benefit from forecasts. Yet the
\end{abstract}

${ }^{\mathrm{a}}$ corresponding author, Department of Agricultural Economics, 400 C.E. Barnhart Building, Lexington, KY 40546-0276, USA, yoko.kusunose@uky.edu

bepartment of Geography and Geology, 304 Environmental Science and Technology 1906 College Height Blvd., Bowling Green, KY 42101-1066, USA, rezaul.mahmood@wku.edu 


\section{${ }_{21}$ Acknowledgements} imperfect information comments and suggestions.

response from farmers, it appears, was not commensurate with the values suggested by the studies. In this article we make the case that forecast quality, both real and perceived, may still pose a significant obstacle; despite recent gains in forecasting ability, forecasts - especially seasonal climate forecastsare far from certain. Unless this uncertainty is explicitly and more realistically incorporated into models of forecast use, a gap will always exist between expectations of forecast use and actual forecast use by farmers. We conclude by establishing the need for 1) making imperfect forecasts a standard feature in models of forecast use and 2) informing these models with empirical research on farmer use of imperfect forecasts.

KEYWORDS: forecast accuracy, weather, climate, agricultural decision making,

This is publication No. 00-00-000 of the Kentucky Agricultural Experiment Station and is published with the approval of the Director. This work is supported by the National Institute of Food and Agriculture, U.S. Department of Agriculture, Hatch Project under 1006174. Additionally, we wish to thank the editors and our three anonymous reviewers for their careful readings of prior drafts, and for their thoughtful 


\section{${ }_{28} 1$ Introduction}

29

\footnotetext{
${ }^{1}$ Examples of commonly modeled management alternatives are crop choice, varietal choice, planting dates, input application rates and input timing.
} 
47 commensurate with the estimated benefits of doing so. This is especially true of

48

longer-term climate information, in contrast to daily or weekly weather forecasts. For a novel source of weather information to have any real marginal value, it must lead to changes in management choices that result in improved outcomes. Clearly, many factors stand between information availability and information use. Limited reliance on new information sources can be a function of multiple factors, including the following: grower objectives and risk preferences, enrollment in risk-management programs (e.g. crop insurance), the inability (financial, physical, or perceived) of changing practices in response to forecasts, the format and quality of the forecasts themselves, and the process by which decision makers assimilate these forecasts (Sonka et al. 1987; Artikov et al. 2006; Cabrera, Letson, and Podestá 2007; Klockow, McPherson, and Sutter 2010; Carriquiry and Osgood 2012). However, the observation that farmers are less responsive to longer-term weather and climate forecasts - combined with the fact that forecasts with longer lead times are generally of lower quality_implies that forecast quality may be a critical factor.

This review focuses on the quality (or uncertainty) of forecasts. First, it provides a general sense of the current quality of forecasts. Second, it summarizes the main modeling approaches used to depict forecast quality in value-of-seasonal-forecast studies to date. Here we find that, while some models of seasonal forecast use allow for imperfect forecasts, they are not nearly as numerous as the ones that assume perfect forecasts. Moreover, the modeling of the assimilation process for imperfect 
77 refined.
79

forecasts appears to be somewhat $a d$ hoc and driven entirely by theory, rather than any empirical tests or observations. Third, this study provides a simple example of a typical model and uses the results of this example to explain the commonly reported observation of many farmers 'paying attention' to forecasts while, at the same time, not 'using' them. This simple model suggests the existence of a critical 'minimum accuracy threshold' that forecasts must surpass in order to be of any practical use. We conclude by establishing the need for i) making uncertainty a standard feature of forecast-use-(and-value) models and ii) improving communication with extension agents and farmers themselves so that basic model assumptions can be vetted and refined.

\section{The current state of weather and climate fore-}

\section{casts}

Over the past two decades, the meteorological and climate community has made steady progress in the accuracy and lead-time of weather and climate forecasts. Yet despite these gains, forecast quality (real and perceived) may still be the primary limitation in forecast use (Hu et al. 2006). In this section we discuss the availability, actual quality, and perceived quality of weather and climate forecasts. 


\section{$2.1 \quad$ Forecast availability}

Some of the most common sources of forecasts in the U.S. include products developed by two entities within the National Oceanic and Atmospheric Administration (NOAA): the National Weather Service (NWS) and the Climate Prediction Center (CPC). Both the NWS and CPC provide interactive, on-line, map-based forecast products. For example, on the NWS website (www.weather.gov), users can select any point on a U.S. map and obtain location-specific forecasts, including maximum and minimum temperatures and precipitation, for the next seven days. Users can also view maps of precipitation forecasts extending up to five days ahead, and hazardous weather outlooks extending up to three days. The CPC website (www.cpc.ncep.noaa.gov) provides 6-to-10-day, 8-to-14-day, monthly, and seasonal outlooks. These forecasts are also presented as color-coded maps showing the probability of above or below-normal occurrences. It also presents a 'Weekly Weather and Crop Bulletin,' a joint publication by NOAA and USDA. Additionally, the two websites provide contextual information for their forecasts, which may be useful to the more weather- and climate-attuned users, and informative for average users as well.

In addition to forecasts disseminated via the NWS and CPC, NOAA provides current-state reports on Pacific Ocean sea surface temperature, as well as outlooks related to El Niño and La Niña events. These are helpful for weather- and climateattuned farmers in the regions affected by El Niño and La Niña. NOAA also offers 


\footnotetext{
${ }^{2}$ Instrumentation exposure is affected by the presence of manmade or natural objects near the observing equipment. For example, if there is a large tree close to wind and precipitation measuring
} 
longer be gauged. In other words, inhomogeneity of instruments within a meteorological network renders the quality of its forecasts 'unknowable.'

\section{$2.2 \quad$ Forecast quality}

The quality of a forecasts depends on many factors. As one would expect, forecasts with longer lead times (i.e. forecasts of conditions that are farther in the future) are generally less accurate than those with shorter lead times. In general, precipitation forecasts are less accurate than temperature forecasts. And, by construction, forecasts of lower resolution (e.g. those that predict the likelihood of three categorical eventsabove average, average, and below average temperatures) are more accurate than those of higher resolution (e.g. those that predict the likelihood of events across five categories).

The quality of forecasts can be described using many, inter-related, general metrics such as accuracy, skill, reliability, sharpness, resolution, and uncertainty (Stanski, Wilson, and Burrows 1989). Of the myriad measures used to quantify these characteristics, here we discuss two: the post agreement rate and the hit rate. These are both measures of accuracy and the two most commonly used parameters to convey forecast uncertainty in forecast use models. Moreover, accuracy measures for select forecast instruments, the tree will obstruct the natural flow of wind, causing inaccuracies in wind speed and direction measurements. As another example, a temperature sensor located close to a building or an asphalt road would record higher temperature than actual air temperatures, introducing bias (Mahmood, Foster, and Logan 2006; Pielke Sr. et al. 2007). 


\section{follows:}

\footnotetext{
${ }^{3}$ These forecasts comprise one narrow class of forecasts among many; however, focusing on this particular forecast type permits the simplest explanation of our concepts.
} 


$$
\begin{aligned}
\text { post-agreement rate, forecast }=\mathrm{El} \mathrm{Niño} & =\frac{\text { correct El Niño forecasts }}{\text { all El Niño forecasts }} \\
& =\frac{a}{a+b+c}
\end{aligned}
$$

In contrast, hit rates, or probabilities of detection, pertain to outcomes. For an El Niño outcome,

$$
\begin{aligned}
\text { hit rate, outcome }=\mathrm{El} \text { Niño } & =\frac{\text { correct El Niño forecasts }}{\text { all El Niño outcomes }} \\
& =\frac{a}{a+d+g} .
\end{aligned}
$$

There is, of course, more to measuring forecast quality than simply comparing forecasts to outcomes, ex post. Widely used to determine the (ex ante) uncertainty of a particular forecast is an ensemble forecast, or a set of closely related forecasts (ensemble members). Recall that forecasts take current (initial) conditions and use models to predict their evolution over time. Since atmospheric processes are complex, a small degree of uncertainty in the initial condition may become large at the end of a forecast period. There is also uncertainty regarding the model itself. Therefore, an ensemble forecast is produced by running multiple models with slightly different initial conditions and/or model parameters. If all ensemble members nonetheless predict similar outcomes, then a high degree of confidence is placed on a forecast for that outcome. It is worth noting that even probabilities forecasted using ensemble forecasts are typically verified against historical event probabilities. For a discussion 
on the advantages and caveats of ensemble forecasts, please see Kharin and Zwiers (2002). Interestingly, when forecast users consult multiple sources, they are, in effect, generating their own 'ensemble forecast.' Intuitively, here too, consistency among the sources should signal a higher degree of certainty surrounding a particular forecast. ${ }^{4}$

It is difficult to find published literature that neatly summarizes the current state of forecast quality. Studies that discuss forecast quality are generally inaccessible to the lay reader, in part, because of the many different measures, the wide variety of forecast types, and the many model and initial condition factors considered. In general, however, the quality of forecasts has improved, especially so for precipitation. For example, recent work suggests that the accuracy of long-range climate forecasts by the $\mathrm{CPC}$ for temperature and precipitation forecasts - measured using the Heidke Skill Score ${ }^{5}$ - have improved approximately $18 \%$ and 195\%, respectively (O'Lenic et al. 2008).

The Climate Prediction Center's website is unique in that it presents forecasts in explicitly probabilistic format. ${ }^{6}$ Regions are designated with percent probabilities -in this case, post-agreement rates ${ }^{7}$ —of experiencing 'above average,' 'below average,' and

\footnotetext{
${ }^{4}$ We thank our anonymous reviewer for this observation.

${ }^{5}$ Skill is a measure the accuracy of forecasts relative to a reference standard, typically random forecasts based on historical event probabilities. In this sense, they convey the informativeness of the forecasts.

${ }^{6}$ We intentionally avoid calling forecasts in probabilistic format 'probabilistic forecasts' since this connotes how forecasts are generated (e.g. ensemble forecasts), rather than how they are presented to users.

${ }^{7}$ Note that the practical interpretation of a post-agreement rate (hit rate) remains the same
} 
'average' temperatures (precipitation). For 6-to-8 day temperature forecasts, these percentages typically range from $33 \%$ (climatological average, by definition) to $80 \%$, meaning that, at least for some regions, higher (lower)-than-average temperatures can be predicted with considerable certainty. On the other hand, for three-month precipitation outlooks, even the highest probabilities rarely exceed $50 \%$, meaning that such forecasts are only slightly more informative than the historical average. Taking these accuracy levels as an indication of the general quality of forecasts, forecasts are indeed still far from perfect.

\subsection{Perceptions of forecast quality}

Perceptions of forecast quality can matter as much as - if not more than - actual forecast quality since, ultimately, it is the farmers' perceptions of forecast quality that drive forecast use. Hu et al. (2006) note, "The fact that the features of forecasts have changed over time but that the use of forecasts by farmers has not changed suggests the need to focus on the internal factors and reevaluate the forecast use and influence from the perspective of farmers, asking the questions concerning not only how farmers perceive forecasts, but also how farmers value those perceptions ( $\mathrm{p}$. 1191)."

The question of how 'reliable' farmers find forecasts has been studied primarily via structured interviews and focus groups (e.g. Changnon (2004), Artikov et al. (2006), regardless of how it is generated - be it from the historical record or, more commonly, ensemble forecasts. 
Crane et al. (2010), Mehta et al. (2013)). Artikov et al. (2006) find that 'attitude' is among the strongest determinants of farmers' likelihood to use weather forecasts. Crucially, their 'attitude' variable is composed of a 'belief' component which the authors generate by asking participants how likely they find weather forecasts to be of use in meeting particular goals, such as conserving water and choosing the best crops and varieties. Crane et al. (2010) conduct ethnographic interviews with 38 farmers in Southern Georgia and summarize, "Although farmers are highly attuned to weather forecasts, their use of such information is hindered by doubts about the information's relevance and accuracy (p. 52)." In particular, the authors find that farmers are less likely to rely on forecasts with greater lead times and, as a result, rarely seek out seasonal climate forecasts. They also note that the majority of interviewed farmers gauge a forecast source's reliability based on personal experience (i.e. how well the forecasts matched up with personally observed outcomes). Similarly, Mehta et al. (2013) report that, although Missouri River Basin farmers are eager for decadal climate outlooks, the 'credibility' of these outlooks remains a primary obstacle to their use. Finally, through a unique long-term study (1981-2001) of climate prediction usage by U.S. agribusinesses, Changnon (2004) shows that, while improvements in availability, accuracy, and lead-time have contributed to increased reliance on climate forecasts over the 21-year period, a perception of low accuracy still keeps many participants from relying on these predictions.

The above studies suggest that perceived forecast quality is an important de- 


\footnotetext{
${ }^{8}$ Granted, the focus of such studies is typically something else, such as risk aversion or prices; for these studies, perfect forecasts is likely a simplifying assumption.
} 
Unlike imperfect forecasts, the definition of a perfect forecast is widely agreed upon. In the case of deterministic, categorical forecasts, it is information that identifies a single event that takes place with certainty. If we think of a single forecast as a signal describing a distribution of probabilities over all of the potential outcome events, then the distribution associated with a perfect forecast is a degenerate distribution with all of its mass at the particular event being forecast. All predictions are realized and, equivalently, all outcomes are correctly predicted.

The typical perfect-forecast study asks, 'given the historical climate/weather record, what would have been the best management practice(s) for each season?' It then calculates the profit stream that would have resulted from using the optimal management practice(s) each season and compares it to that which would have resulted from implementing the static optimal management practice(s). Three examples of such studies are Jones et al. (2000), Hansen et al. (2001), and Messina, Hansen, and Hall (1999). From a decision modeling standpoint, this is equivalent to assuming that the decision maker i) receives perfect forecasts and ii) perfectly adopts the transmitted signal - that is, the decision maker's personal, post-forecast probability distribution of events (i.e. her posterior distribution) is identical to the one that was forecasted. This second assumption of perfect adoption is reasonable given the assumption of perfect forecasts; if the forecasts are never wrong, why should the decision maker act as if otherwise? Thus, within the class of studies that assume perfect forecasts, there is consistency in the definition of a forecast and the process by which it is assimilated 
by the decision maker; in the presence of perfect forecasts, the decision maker simply 'knows' ex ante what the outcome will be, and takes the action that would generate the most profit or utility.

Once studies allow for imperfect forecasts, they begin to diverge in their modeling approaches. However, the literature shows two basic approaches: i) incorporating the uncertainty into the decision maker's posterior distribution and ii) incorporating it into the decision maker's belief, or likelihood matrix, and then assuming Bayesian updating. As will become clear, the two modeling approaches are closely related to each other. ${ }^{9}$

Continuing our example of the three ENSO phases, the following $3 \times 3$ matrix gives the probabilities that the decision maker places on each outcome (in the rows), given particular forecasts (in the columns). This is a posterior matrix; it gives all of the probabilities that the decision maker places on each event taking place, conditional on the forecasts.

$$
\text { forecast }=\mathrm{El} \text { Niño } \text { forecast }=\text { Neutral } \text { forecast }=\text { La Niña }
$$

$$
\begin{array}{lccc}
\text { outcome }=\text { El Niño } & p(E \mid E) & p(E \mid N) & p(E \mid L) \\
\text { outcome }=\text { Neutral } & p(N \mid E) & p(N \mid N) & p(N \mid L) \\
\text { outcome }=\text { La Niña } & p(L \mid E) & p(L \mid N) & p(L \mid L)
\end{array}
$$

One way to model imperfect forecasts is to build the uncertainty directly into the

\footnotetext{
${ }^{9}$ These approaches are also consistent with the framework and behavioral assumptions used in cost-loss analyses. We do not discuss cost-loss analyses of forecast quality any further in this paper except to refer the reader to Zhu et al. (2002) and Palmer (2002) for examples.
} 
above matrix, by assigning the diagonal elements of the matrix values of less than one, and the off-diagonal elements values greater than zero. This is the approach taken by Katz, Brown, and Murphy (1987), Sonka et al. (1987), Mjelde et al. (1993), Mjelde, Hill, and Griffiths (1998) and Adams et al. (2003). If forecasts are categorical and presented in non-probabilistic format, as in our example, the diagonal elements are equivalent to the post-agreement rates (PAR) of the forecasts. For example, Sonka et al. (1987) vary the PAR from 1 (perfect forecasts) to 0.72 for three categories of growing conditions for three decision stages and varying lead times for corn producers in east central Illinois. Using the same setting, Mjelde, Hill, and Griffiths (1998) vary the PAR between 1 and 0.44 for five categories of growing conditions at eight decision junctures throughout the growing season. Adams et al. (2003) consider PARs of 1 and 0.7 for three ENSO states (El Niño, La Niña, and Neutral) across several Mexican states. Using a slightly different approach, Meza and Wilks (2003) predict three-month ahead ENSO states from sea surface temperatures for Chilean rain-fed agriculture. They use both a discrete Markov process and an autoregressive process; the discrete Markov process has PARs of approximately 0.6 for El Niño and La Niña states.

Other studies go back one step further and explicitly model the belief-updating process - that is, the process of a decisionmaker using forecasts to update her prior distribution to then arrive at her posterior distribution (e.g. Solow et al. (1998), Adams et al. (1995)). Here, the posterior distribution is a function of two things: the 
'likelihood' matrix and the prior distribution. It is assumed that the decision maker uses Bayesian updating. Given a particular forecast $k$, the probability of event $n$ taking place (i.e. the outcome being $n$ conditional on having received the forecast $k$ ) is

$$
p(o=n \mid f=k)=\frac{\pi(f=k \mid o=n) h(o=n)}{\sum_{N} \pi(f=k \mid o=n) h(o=n)}
$$

where $\pi(f=k \mid o=n)$ denotes the probability of receiving forecast $k$ conditional on the outcome $n$ and $h(o=n)$ is the absolute probability of event $n$ (i.e. the prior). Using our ENSO-phase example above, the decision-maker's belief about the probability of the outcome being, say, El Niño conditional on having received the forecast 'El Niño' $(p(o=\mathrm{El} \mathrm{Niño} \mid f=\mathrm{El}$ Niño $))$ is a function of the absolute likelihood of an El Niño outcome $(h(o=$ El Niño $))$, her perception of how frequently the signal matches the true outcome $(\pi(f=$ El Niño $\mid o=$ El Niño $))$, and the absolute likelihood of an El Niño forecast $\left(\sum_{n=E, N, L} \pi(f=\right.$ El Niño $\left.\mid o=n) h(o=n)\right)$. Arranging all of the resultant posterior probabilities in a single matrix, we arrive at the same $N$-by- $K$ matrix as above.

If we take the user's perceptions of how frequently forecasts match the outcomes $(\pi(f=k \mid o=n))$ and arrange these in a matrix, we have the $K$-by-Nlikelihood $m a$ trix: 
322

323

outcome $=$ El Niño outcome $=$ Neutral outcome $=$ La Niña

$$
\text { forecast }=\text { El Niño } \quad \pi(E \mid E) \quad \pi(E \mid N) \quad \pi(E \mid L)
$$$$
\text { forecast }=\text { Neutral } \quad \pi(N \mid E) \quad \pi(N \mid N) \quad \pi(N \mid L)
$$

forecast $=$ La Niña $\quad \pi(L \mid E) \quad \pi(L \mid N) \quad \pi(L \mid L)$

When Bayesian updating is assumed, the uncertainty of forecasts is built into this matrix. Again, assuming that the set of possible forecasts is identical to the set of potential states of the world, now the diagonal elements of this likelihood matrix correspond to the hit rates for every possible event. Given a perfect information source, each of these diagonal elements will take the value of one, and all of the off-diagonal elements, zero. To model imperfect forecasts, the diagonal elements are assigned values of less than one, and the off-diagonal elements are permitted to be greater than zero. For example, Adams et al. (1995) quantify the effect of increased forecast skill by increasing the diagonal elements from 0.6 to 0.8 . Note that if the likelihood matrix depicts forecast uncertainty (i.e. it has hit rates of less than one), the resultant posterior matrix will reflect this uncertainty with post-agreement rates of less than one.

It is generally assumed that the posterior matrices and likelihood matrices correctly reflect the accuracy of forecasts. That is, the decision makers correctly assess the uncertainty of the forecasts. It is also typically assumed that decision makers' priors are based on climatological, or historical probabilities - in other words, that their prior distributions are 'correct.' However, none of these assumptions have been 
formally tested, leading some to investigate their consequences: For example, Mjelde et al. (1988) present a rare illustration of the effect of the assumed prior distribution: they consider four different types - climatological, prior year, 'pessimistic' (worstcase), and 'optimistic' (best case) — and find that expected net returns are, indeed, sensitive to the assumed prior distribution, but not necessarily in predictable ways. Sonka et al. (1987) note that the use of climatological distributions as prior beliefs tends to underestimate the value of forecasts (p. 1086).

To summarize, the imperfect nature of forecasts is represented either through posterior matrices or likelihood matrices. Where the updating mechanism is modeled, decision makers are assumed to arrive at 'correct' posterior distributions by perfectly updating their priors. With very few exceptions, these priors are also assumed to be 'correct' - that is, the prior distributions of the farmers are identical to the absolute (unconditional on forecasts) probability distributions of the outcomes. Decision makers are then assumed to make management decisions consistent with their posterior beliefs. That is, decision makers perfectly assimilate imperfect forecasts.

\section{The value of imperfect forecasts: a simple ex-} ample

Value estimates of forecast sources, or information systems in general, are generated by comparing the value stream resulting from the decision maker's actions in the 
presence of forecasts (or 'better' forecasts), to that resulting from their absence (or reference forecasts). ${ }^{10}$ Thus forecasts have value only when i) they cause decision makers to choose actions that they would not not have otherwise chosen and ii) when these actions lead, on average, to better outcomes.

Intuitively, when forecasts are less than perfect, their value is lower. Obviously, when the forecast is incorrect some of the time, even the 'right' strategy can lead, at times, to retrospectively 'wrong' decisions. ${ }^{11}$ Less obvious is that even in the presence of skilled forecasts, decision makers may not change their management strategies. If the management strategies remain unchanged, forecasts, however skilled, have zero value. A critical question, then, is 'how skilled must forecasts be to induce changes in management practices and thereby begin generating welfare improvements for farmers?'

Empirical evidence suggests the existence of a 'minimum-reliability threshold,' below which the cognitive costs of seeking and assimilating a new (and possibly superior) forecast source outweighs the expected benefit of doing so (See, for example, Hayman et al. (2007) for a synthesis of the literature on seasonal climate forecast ac-

\footnotetext{
${ }^{10}$ Such value-of-information studies have been undertaken for various agricultural settings with different management choice sets (e.g. crop choice, planting dates, fallowing, fertilizer application) and forecast types (e.g. ENSO phase, SOI phase, rainfall terciles). For a comprehensive list, please see Meza, Hansen, and Osgood (2008).

${ }^{11} \mathrm{~A}$ 'strategy' is defined as a complete set of decision rules for every possible forecast. For example, 'If the forecast is El Niño, take action A; if the forecast is neutral, take action B; and if the forecast is La Niǹa, take action C.'
} 
curacy and forecast adoption in Australia.). However, even absent such psychological thresholds, existing models of imperfect forecast use suggest the existence of critical threshold levels of forecast skill below which forecasts have no value whatsoever (e.g. Moeller et al. (2008), Millner (2008)). That is, even if decision makers 'pay attention' to forecasts, depending on their accuracy levels, they may not induce changes in management practices, meaning that the forecasts still provide zero value. Millner (2008) makes this point with a flexible, generalized theoretical model of Bayesian updating with imperfect forecasts and explores the sensitivity of this result to various factors, including the nature of the management problem and the assumed risk preferences.

Here, we provide a more qualitative and much simplified example: a cropping model based on imperfect ENSO forecasts. Our model is loosely based on the wheatsoybean-peanut-maize system in Tifton, Georgia described by Jones et al. (2000) and uses their estimates of output prices and per-area input costs. However, in order to maintain the focus on the mechanism of forecast assimilation, we have assumed away many layers of complexity that typically make such models more realistic.

Every season, our farmer must choose one crop from among maize, wheat, and soybean. ${ }^{12}$ The objective of the farmer is to maximize his expected profit, and his decision each year is based on the (imperfect) forecast of the ENSO phase. Suppose the following: Maize yields are 10\% higher in La Niña years, $10 \%$ lower in El Niño years, and average $(5.82 \mathrm{Mg} / \mathrm{ha})$ in neutral years; wheat yields are $7 \%$ lower in La

\footnotetext{
${ }^{12} \mathrm{We}$ exclude peanuts for the sake of simplcity.
} 
Niña years, $7 \%$ higher in El Niño years, and average (4.0 Mg/ha) in neutral years; finally, soybean yields are constant $(2.4 \mathrm{Mg} / \mathrm{ha})$ across all three phases. ${ }^{13}$ Lastly, assume that the three phases and their forecasts occur with equal probability.

We depict the uncertain nature of the forecasts by assuming that the farmer, given a particular forecast (e.g. "It will be an El Niño (neutral, La Niña) year"), trusts that it will most likely be an El Niño (neutral, La Niña) year but also understands that the forecast will be wrong some of the time. That is, the post-agreement rate (PAR) for all three signal types can be less than unity. Using the terminology from above, we assume the farmer's matrix of posterior probabilities to be

$\begin{array}{cccc} & \text { forecast=El Niño } & \text { forecast=neutral } & \text { forecast=La Niña } \\ \text { outcome= El Niño } & g & (1-g) / 2 & (1-g) / 2 \\ \text { outcome= neutral } & (1-g) / 2 & g & (1-g) / 2 \\ \text { outcome= La Niña } & (1-g) / 2 & (1-g) / 2 & g\end{array}$

where $g$ is the PAR and $.3 \overline{3} \leq g \leq 1$. For the sake of simplicity, we use the same PAR for all three forecast types.

Suppose that the farmer's perception of the forecasts' accuracy is identical to the actual accuracy of the forecasts and this accuracy is described by $g$. For every level of $g$, the farmer chooses an ex ante management strategy. An example strategy is "If the forecast is El Niño, I will plant wheat; if it is La Niña, I will plant maize,

${ }^{13}$ The qualitative yield responses to ENSO phases, if not the exact percentages, are based on Hansen et al. (1998). The baseline yields are made up by the authors. 
and if it is neutral, I will plant soybean." Given our example, this is, in fact, the optimal strategy when $g=1$, or the forecasts are perfect. The farmer arrives at this and all other strategies by calculating, for each forecast, the expected profit from planting each crop and then choosing the crop that yields the highest expected profit conditional on the forecast. ${ }^{14}$ The expected value of the farmer's strategy is calculated by multiplying the expected profit of each optimal action (conditional on the forecast) by the frequency of each forecast. A formal statement of the problem and specific formulae can be found in the Appendix.

The table below shows how the optimal strategy varies as the PAR ranges from $.3 \overline{3}$ to 1 . In this example, a PAR of $.3 \overline{3}$ means that, given a forecast $f=k$ $(k \in\{$ El Niño, neutral, La Niña $\})$ the posterior probability of the outcome being $k$ is identical to the prior probability of outcome $k .^{15}$ This is equivalent to i) absent forecasts, the decision maker relying strictly on his prior distribution and ii) the decision maker hearing forecasts that are unbiased but completely uninformative (i.e. the forecasts are random draws from the historical probability distribution).

\footnotetext{
${ }^{14}$ By making the maximand-or the value to be maximized-expected profit, we inherently assume risk-neutrality on the part of the farmer. However, it is just as common for models to assume that the farmer chooses the management strategy that maximizes his/her expected utility or some other preference function. Doing so here would have unnecessarily complicated the example.

${ }^{15}$ Specifically, if the forecast is 'El Niño,' for example, $\operatorname{pr}(o=E \mid f=E)=\operatorname{pr}(o=E)=.3 \overline{3}$.
} 


\begin{tabular}{cccccc}
\hline PAR & \multicolumn{2}{c}{ optimal strategy } & E[profit] & Value of information \\
$(\mathrm{g})$ & El Niño & neutral & La Niña & $(\$ /$ ha $)$ & $(\$ /$ ha $)$ \\
\hline 1.0 & wheat & soybean & maize & 262.07 & 11.52 \\
0.9 & soybean & soybean & maize & 258.20 & 7.65 \\
.8 & soybean & soybean & maize & 255.26 & 4.71 \\
.7 & soybean & soybean & maize & 252.33 & 1.78 \\
.6 & soybean & soybean & soybean & 250.55 & 0 \\
.5 & soybean & soybean & soybean & 250.55 & 0 \\
.4 & soybean & soybean & soybean & 250.55 & 0 \\
.$\overline{3}$ & soybean & soybean & soybean & 250.55 & 0 \\
\hline
\end{tabular}

\footnotetext{
${ }^{16}$ While it is highly unrealistic that a farmer would switch crops on a whole-farm basis, this is a result of our simplifying model assumptions.

${ }^{17}$ The same qualitative result would have been obtained under risk aversion.
} 
This simple example illustrates that even if skilled forecasts are available, and even if farmers are attuned to these forecasts, forecasts may have no value if they are not 'accurate enough.' It is consistent with the numerous studies reporting large percentages of farmers being aware of forecasts but far smaller percentages 'using the forecasts,' or incorporating the forecasts into their management practices in discernible ways.

\section{Conclusion and recommendations}

The past few decades saw tremendous advances in weather and climate forecasting ability. These improvements opened up the possibility of strategic adaptation of agricultural management in anticipation of weather and climate outcomes, resulting in a profusion of studies estimating the value of weather and climate forecasts. Estimated values from this literature were, in many cases, substantive, implying that farmers could significantly benefit from forecasts. Yet the response from farmers, to date, does not appear commensurate with the values suggested by the studies.

A farmer's decision to rely on a forecast source is likely a function of many things— here, we make the case that forecast quality may still pose a significant obstacle. Despite recent gains in forecasting ability, forecasts - especially those for the longer term - are far from certain. It is possible that forecasts are still not 'certain enough' for the purposes of strategic agricultural management, but the vast majority of our current models of forecast use do not allow for such a possibility. Even the second- 
generation, imperfect-forecast models are oftentimes calibrated to consider farmer behavior in response to forecasts over unrealistically high ranges of accuracy. Moreover, our applied theoretical models appear, for the most part, to be happily self replicating, completely independent of the growing, (albeit qualitative) empirical literature on forecast quality, farmer perceptions of forecast quality, and farmer use of imperfect forecasts.

Estimates of climate and weather forecasts value will continue to generate unrealistic results unless forecast assimilation models better reflect actual forecast quality levels and farmer behavior. Obtaining meaningful models of forecast use requires the convergence of our models with real farmer behavior. The obvious, but difficult, solution is to nudge our models closer to observed farmer behavior. To this end, we have two recommendations:

Make forecast uncertainty a standard feature in models of forecast use and value. Models should reflect the imperfect nature of forecasts. Not only should studies assume less-than-perfect forecasts, but they should simulate decision-making behavior in response to a wider (and lower) range of accuracy levels. They should make explicit their hypothesized models of forecast assimilation - that is, how farmers weigh forecasts against their subjective priors (if at all), the bases of these priors, and the translation of this information into management decisions. Most importantly, these model assumptions should be explicitly tested and continually updated based on em- 
pirical findings.

Empirically test assumptions of forecast assimilation and let the findings inform future models.

Some empirical studies of farmer forecast use exist—see, for example, Artikov et al. (2006), Hu et al. (2006) and Marx et al. (2007) — however, these studies do not necessarily test for specific assumptions made in models of imperfect forecast use. For example, below a certain perceived level of accuracy, farmers may ignore forecasts altogether; at higher levels, they may update their priors; and at still higher levels of accuracy, they may treat forecasts as perfect. However, without any sort of input from those on the ground, observing (i.e. sociologists, extension agents, and farmers themselves), this all remains speculation.

It is not at all surprising that models of forecast use have never been tested empirically when one considers the 'ideal' dataset: panel data on forecasts, forecast accuracy measures, and farmer responses. Such data are difficult, if not impossible, to find observationally. Nonetheless, this empirical void could be filled with data from framed field experiments (for example, something akin to Menapace, Colson, and Raffaelli (2012)) or, at the least, qualitative interviews and focus groups designed specifically to vet models of forecast use.

This latter recommendation is a restatement of the perennial 'ivory tower' problemor rather, the 'ivory towers' problem - in that adequate communication is not taking 
place between the disciplines (the towers), much less between the modelers and those they claim to model. Howden et al. (2007) note that challenges that are multidisciplinary in nature require multi-disciplinary solutions. Pielke Jr. and Carbone (2002) claim that the U.S. has not yet fully benefited from public investment in the 'weather prediction enterprise.' They note, "For the process to work effectively, success is necessary in all three elements of the forecast process: prediction, communication, and use (p. 400)." While the authors' statement here refers to the actual use of forecasts, the same is true of our models of use; absent increased efforts to integrate farmer input and empirical observations of forecast use into our models, we can never hope to estimate the true value of the burgeoning 'weather prediction enterprise.' 


\section{${ }_{511}$ References}

${ }_{512}$ Adams, R.M., K.J. Bryant, B.A. McCarl, D.M. Legler, J. O’Brien, A. Solow, and

${ }_{513}$ R. Weiher. 1995. "Value of improved long-range weather information." Contempo$514 \quad$ rary Economic Policy 13:10-19.

515 Adams, R.M., L. Houston, B. McCarl, M. Tiscareño, J. Matus, and R. Weiher. 2003.

${ }_{516}$ "The benefits to Mexican agriculture of an El Niño-Southern Oscillation early warn$517 \quad$ ing system." Agricultural and Forest Meteorology 115:183-194.

${ }_{518}$ Artikov, I., S.J. Hoffman, G.D. Lynne, L.M. PytlikZillig, Q. Hu, A.J. Tompkins, ${ }_{519}$ K.G. Hubbard, M.J. Hayes, and W. Waltman. 2006. "Understanding the influence ${ }_{520}$ of climate forecasts on farmer decisions as planned behavior." Journal of Applied $521 \quad$ Meteorology and Climatology 45:1202-1214.

Baars, J., and C. Mass. 2005. "Performance of National Weather Service forecasts compared to operational, consensus, and weighted model output statistics." Weather and Forecasting 20:1034-1047.

Cabrera, V.E., D. Letson, and G. Podestá. 2007. "The value of climate information when farm programs matter." Agricultural Systems 93:25-42.

Carriquiry, M.A., and D.E. Osgood. 2012. "Index insurance, probabilistic climate forecasts, and production." The Journal of Risk and Insurance 79:287-299. 
Changnon, S. 2004. "Changing uses of climate predictions in agriculture: implications for prediction research, providers, and users." Weather and Forecasting 19:606-613.

Charba, J., and F. Samplatsky. 2011. "High-resolution GFS-based MOS quantitative precipitation forecasts on a 4-km grid." Monthly Weather Review 139:39-68.

Crane, T., C. Roncoli, J. Paz, N. Breuer, K. Broad, K. Ingram, and G. Hoogenboom. 2010. "Forecast skill and farmers' skills: seasonal climate forecasts and agricultural risk management in the Southeastern United States." Weather, Climate, and Society 2:44-59.

Ebert, E., J. Janowiak, and C. Kidd. 2007. "Comparison of real-time precipitation estimates from satellite observations and numerical models." Bulletin of the American Meteorological Society 88:47-64.

Hansen, J., J. Jones, A. Irmak, and F. Royce. 2001. "El Niño-Southern Oscillation impacts on crop production in the southeast United States." In C. R. et al., ed. Impacts of El Niño and Climate Variability on Agriculture. American Society of Agronomy, no. 63 in ASA Special Publication, pp. 55-76.

Hansen, J., J.W. Jones, A. Irmak, and F. Royce. 1998. "ENSO Impacts on Crop Production in the Southeast US." Presented at the Proceedings of the American Society of Agronomy.

Hayman, P., J. Crean, J. Mullen, and K. Parton. 2007. "How do probabilistic sea- 
sonal climate forecasts compare with other innovations that Australian farmers are encouraged to adopt?" Australian Journal of Agricultural Research 58:975-984.

Howden, S.M., J.F. Soussana, F. Tubiello, N. Chhetri, M. Dunlop, and H. Meinke. 2007. "Adapting agriculture to climate change." Proceedings of the National Academy of Sciences of the USA 104:19691-19696.

Hu, Q., L. PytlikZillig, G. Lynne, A. Tomkins, W. Waltman, M. Hayes, K. Hubbard, I. Artikov, S. Hoffman, and D. Wilhite. 2006. "Understanding farmers' forecast use from their beliefs, values, social norms, and perceived obstacles." Journal of Applied Meteorology and Climatology 45:1190-1201.

Jones, J., J. Hansen, F. Royce, and C. Messina. 2000. "Potential benefits of climate forecasting to agriculture." Agriculture, Ecosystems, and Environment 82:169-184.

Katz, R.W., B.G. Brown, and A.H. Murphy. 1987. "Decision-analytic assessment of the economic value of weather forecasts: the fallowing/planting problem." Journal of Forecasting 6:77-89.

Kharin, V., and F. Zwiers. 2002. "Climate predictions with multimodel ensembles." Journal of Climate 15:793-799.

Klockow, K.E., R.A. McPherson, and D.S. Sutter. 2010. "On the economic nature of crop production decisions using the Oklahoma Mesonet." Weather, Climate, and Society 2:224-236. 
Magnusson, L., and E. Källén. 2013. "Factors influencing skill improvements in the ECMWF forecasting system." Monthly Weather Review 141:3142-3153.

Mahmood, R., S. Foster, and D. Logan. 2006. "The GeoProfile metadata, exposure of instruments, and measurement bias in climatic record revisited." International Journal of Climatology 26:1091-1124.

Marx, S., E.U. Weber, B.S. Orlove, A. Leiserowitz, D.H. Krantz, C. Roncoli, and J. Phillips. 2007. "Communication and Mental Processes: Experiential and analytic processing of uncertain climate information." Global Environmental Change 17:4758.

McEnery, J., J. Ingram, Q. Duan, T. Adams, and L. Anderson. 2005. "NOAA's advanced hydrologic prediction service: building pathways for better science in water forecasting." Bulletin of the American Meteorological Society 86:375-385.

Mehta, V., C.L. Knutson, N. Rosenberg, J. Olsen, N. Wall, T. Bernadt, and M. Hayes. 2013. "Decadal climate information needs of stakeholders for decision support in water and agriculture production sectors: A case study in the Missouri River Basin." Weather, Climate, and Society 5:27-42.

Menapace, L., G. Colson, and R. Raffaelli. 2012. "Risk aversion, subjective beliefs, and farmer risk management strategies." American Journal of Agricultural Economics 95:384-389. 
Messina, C., J. Hansen, and A. Hall. 1999. "Land allocation conditioned on El NiñoSouthern Oscillation phases in the Pampas of Argentina." Agricultural Systems, pp. 197-212.

Meza, F.J., J.W. Hansen, and D. Osgood. 2008. "Economic value of seasonal climate forecasts for agriculture: review of ex-ante assessments and recommendations for future research." Journal of Applied Meteorology and Climatology 47:1269-1286.

Meza, F.J., and D. Wilks. 2003. "Value of operational forecast of seasonal average sea surface temperature anomalies for selected rain-fed agricultural locations of Chile." Agricultural and Forest Meteorology 116:137-158.

Millner, A. 2008. "Getting the most out of ensemble forecasts: a valuation model based on user-forecast interactions." Journal of Applied Meteorology and Climatology 47:2561-2571.

Mjelde, J.W., H. Hill, and J. Griffiths. 1998. "A review of current evidence on climate forecasts and their economic effects in agriculture." American Journal of Agricultural Economics 80:1089-1095.

Mjelde, J.W., D. Peel, S.T. Sonka, and P.J. Lamb. 1993. "Characteristics of climate forecast quality: implications for economic value to Midwestern corn producers." Journal of Climate 6:2175-2187.

Mjelde, J.W., S.T. Sonka, B.L. Dixon, and P.J. Lamb. 1988. "Valuing Forecast Char- 
acteristics in a Dynamic Agricultural Production System." American Journal of Agricultural Economics 70:674-684.

Moeller, C., I. Smith, S. Asseng, F. Ludwig, and N. Telcik. 2008. "The potential value of seasonal forecasts of rainfall categories-case studies from the wheatbelt in Western Australia's Mediterranean region." Agricultural and Forest Meteorology 148:606-618.

O'Lenic, E., D. Unger, M. Halpert, and K. Pelman. 2008. "Developments in operational long-range climate prediction at CPC." Weather and Forecasting 23:496-515.

Palmer, T. 2002. "The economic value of ensemble forecasts as a tool for risk assessment: From days to decades." Quarterly Journal of the Royal Meteorological Society 128:747-774.

Pielke Jr., R., and R.E. Carbone. 2002. "Weather impacts, forecasts, and policy: an integrated perspective." Bulletin of the American Meteorological Soceity 83:393403.

Pielke Sr., R., C. Davey, D. Niyogi, S. Fall, J. Steinweg-Woods, K. Hubbard, X. Lin, M. Cai, Y.K. Lim, J. Nielsen-Gammon, K. Gallo, R. Hale, R. Mahmood, S. Foster, R. McNider, and P. Blanken. 2007. "Unresolved issues with the assessment of multidecadal global land surface temperature trends." Journal of Geophysical Research: Atmospheres 112. 
Ruth, D., B. Glahn, V. Dagostaro, and K. Gilbert. 2009. "The performance of MOS in the digital age." Weather and Forecasting 24:504-519.

Saha, S., S. Nadiga, C. Thiaw, J. Wang, W. Wang, Q. Zhang, H. Van den Dool, H.L. Pan, S. Moorthi, D. Gehringer, D. Stokes, M. Peña, S. Lord, G. White, W. Ebisuzaki, P. Peng, and P. Xie. 2006. "The NCEP climate forecast system." Journal of Climate 19:3483-3517.

Solow, A.R., R.F. Adams, K.J. Bryant, D.M. Legler, J.J. O’Brien, B.A. McCarl, W. Nayda, and R. Weiher. 1998. "The value of improved ENSO prediction to U.S. agriculture." Climatic Change 39:47-60.

Sonka, S.T., J.W. Mjelde, P.J. Lamb, S.E. Hollinger, and B.L. Dixon. 1987. "Valuing climate forecast information." Journal of Climate and Applied Meteorology 26:1080-1091.

Stanski, H.R., L.J. Wilson, and W.R. Burrows. 1989. "Survey of common verification methods in meteorology." World Weather Watch Technical Report No. 8, World Meteorological Organization, July.

Stensrud, D.J., L. Wicker, K. Kelleher, M. Xue, M. Foster, J.T. Schaefer, R.S. Schneider, S.G. Benjamin, S.S. Weygandt, J. Ferree, and J. Tuell. 2009. "Convective-scale warn-on-forecast system." Bulletin of the American Meteorological Society 90:14871499. 
Yussouf, N., and D.J. Stensrud. 2006. "Prediction of near-surface variables at independent locations from a bias-corrected ensemble forecasting system." Monthly Weather Review 134:3415-3424.

Zhu, Y., Z. Toth, R. Wobus, D. Richardson, and K. Mylne. 2002. "The economic value of ensemble-based weather forecasts." Bulletin of the American Meteorological Society 83:73-83. 


\section{Appendix: Formal statement of the example}

The decision maker's problem and choice set

Each year, the farm manager is faced with the problem of what to plant on his farm: maize $(\mathrm{m})$, soybean $(\mathrm{s})$, or wheat $(\mathrm{w})$. His objective is to maximize his expected per-area profit.

His whole-farm profit in any season is a function of his crop choice ( $a \in \mathbf{A}=$ $\{m, s, w\})$, the ENSO phase outcome $(o \in\{E, N, L\})$, the output prices of the crops $\left(p_{m}, p_{s}, p_{w}\right)$, and the per-area input costs for the crops $\left(c_{m}, c_{s}, c_{w}\right)$. We assume constant crop prices and production costs. The prices (in USD/Mg) are 101 for maize, 222 soybeans, and 120 for wheat. The costs (in USD/ha) are 364 for maize, 282 for soybeans, and 260 for wheat. Prices and input costs are derived from Jones et al. (2000). The yield $(y)$ for each crop is a function of the ENSO phase; we assume the following yields (in $\mathrm{Mg} / \mathrm{ha}$ ):

$$
\begin{array}{lll}
y_{m}(E)=5.24 & y_{m}(N)=5.82 & y_{m}(L)=6.40 \\
y_{s}(E)=2.40 & y_{s}(N)=2.40 & y_{s}(L)=2.40 \\
y_{w}(E)=4.28 & y_{w}(N)=4.00 & y_{w}(L)=3.72
\end{array}
$$

Per-acre profit depends on the crop choice and the ENSO phase outcome:

$$
\text { profit }=j(a, o)= \begin{cases}p_{m} y_{m}(o)-c_{m} & \text { if } a=m \\ p_{s} y_{s}(o)-c_{s} & \text { if } a=s \\ p_{w} y_{w}(o)-c_{w} & \text { if } a=w\end{cases}
$$


Prior to planting, the farmer receives a forecast $f(f \in\{E, N, L\})$. He understands that any particular signal will be correct $g \%$ of the time, and when it is incorrect, the odds are evenly split between the two non-forecasted outcomes. (Please see the posterior matrix in the main text.) For each of the three potential forecasts, the farmer must decide what his best response will be. To do this, he vets all three crops and chooses the one that results in the highest expected profit, conditional on the forecast. For example, for the forecast 'El Niño', the expected profit of any one alternative $a$ is

$$
\begin{aligned}
E[\text { profit } \mid f=E, a] & =\sum_{k=\{E, N, L\}} \operatorname{pr}(o=k \mid f=E) j(a, k) \\
& =g \cdot j(a, E)+(1-g / 2) \cdot j(a, N)+(1-g / 2) \cdot j(a, L) .
\end{aligned}
$$

The best response $a_{E}^{*}$ to the El Niño forecast is

$$
a_{E}^{*}=\max _{a \in \mathbf{A}} E[\text { profit } \mid f=E, a] .
$$

By repeating this process for the two remaining forecasts, he farmer identifies his optimal strategy $\left\{a_{E}^{*}, a_{N}^{*}, a_{L}^{*}\right\}$ from the choice set $\mathbf{A} \times \mathbf{A} \times \mathbf{A}$.

\section{The expected value of the optimal strategy}

The expected value of the optimal strategy is the sum of the expected profits from using the best response to each forecast, weighted by the frequency of each forecast.

$$
E[\text { profit }]^{*}=\sum_{k=\{E, N, L\}} \operatorname{pr}(f=k) E\left[\text { profit } \mid f=k, a_{k}^{*}\right]
$$


Although it is not readily apparent in equation 2 above, the optimal strategy - and therefore expected profit - is very much a function of the accuracy measure $g$, as equation 1 shows.

The value of forecasts and increases in forecast quality

The monetary value of information is defined as the difference in expected value of decisions made in the presence of the information and the expected value of decisions made in its absence. Similarly, the value of increasing the accuracy of the information is the difference in expected value between decisions made using the improved information and those made using information of some reference accuracy level. In this example, we use as our reference the expected value of the optimal strategy based on a scenario in which there are no forecasts or, equivalently, one in which there are forecasts, but they are completely uninformative $(P A R=.3 \overline{3})$. In such a situation, we assume that the farmer would have chosen a single crop $\hat{a}$ that solves the following problem:

$$
\max _{\hat{a} \in \mathbf{A}} E[\text { profit } \mid \hat{a}]
$$

where $E[$ profit $\mid \hat{a}]=\operatorname{pr}(o=E) j(\hat{a}, E)+\operatorname{pr}(o=N) j(\hat{a}, N)+\operatorname{pr}(o=L) j(\hat{a}, L)$

93 Here the farmer identifies the cropping pattern that yields the highest expected profit, on average. It is a static strategy in that the farmer will do the same thing each season. Our baseline value is the maximand to the above problem:

$$
E[\text { profit }]^{*}=\operatorname{pr}(o=E) j\left(\hat{a}^{*}, E\right)+\operatorname{pr}(o=N) j\left(\hat{a}^{*}, N\right)+\operatorname{pr}(o=L) j\left(\hat{a}^{*}, L\right)
$$


${ }_{696}$ The value of information - or having the forecasts - is the difference in expected profit ${ }_{697}$ between the optimal dynamic strategy (equation 2) and the optimal static strategy 698 (equation 3). 